\title{
Ultraviolet imaging spectrometer (UVS) experiment on board the NOZOMI spacecraft: Instrumentation and initial results
}

\author{
M. Taguchi ${ }^{1}$, H. Fukunishi ${ }^{2}$, S. Watanabe ${ }^{3}$, S. Okano ${ }^{1}$, Y. Takahashi ${ }^{2}$, and T. D. Kawahara ${ }^{4}$ \\ ${ }^{1}$ National Institute of Polar Research, Tokyo 173-8515, Japan \\ ${ }^{2}$ Department of Geophysics, Tohoku University, Sendai 980-8578, Japan \\ ${ }^{3}$ Department of Earth and Planetary Science, Hokkaido University, Sapporo 060-0810, Japan \\ ${ }^{4}$ Department of Information Engineering, Shinshu University, Nagano 380-0922, Japan
}

(Received March 18, 1999; Revised September 20, 1999; Accepted October 19, 1999)

\begin{abstract}
An ultraviolet imaging spectrometer (UVS) on board the PLANET-B (NOZOMI) spacecraft has been developed. The UVS instrument consists of a grating spectrometer (UVS-G), an absorption cell photometer (UVS-P) and an electronics unit (UVS-E). The UVS-G features a flat-field type spectrometer measuring emissions in the FUV and MUV range between $110 \mathrm{~nm}$ and $310 \mathrm{~nm}$ with a spectral resolution of 2-3 nm. The UVS-P is a photometer separately detecting hydrogen $(\mathrm{H})$ and deuterium (D) Lyman $\alpha$ emissions by the absorption cell technique. They take images using the spin and orbital motion of the spacecraft. The major scientific objectives of the UVS experiment at Mars and the characteristics of the UVS are described. The MUV spectra of geocoronal and interplanetary Lyman $\alpha$ emissions and lunar images taken at wavelength of hydrogen Lyman $\alpha$ and the background at $170 \mathrm{~nm}$ are presented as representative examples of the UVS observations during the Earth orbiting phase and the Mars transfer phase.
\end{abstract}

\section{Introduction}

Due to a weak or no intrinsic magnetic field on Mars, the solar wind plasma can deeply penetrate into the Martian atmosphere. This penetration is a source of many atmospheric effects, including constituent removal, heating by a variety of processes, and induced magnetization. The atmospheric deuterium to hydrogen abundance ratio $(\mathrm{D} / \mathrm{H}$ ratio) is also an important parameter to investigate the escape processes of the atmosphere of non-magnetic planets such as Mars and Venus. Accurate measurements of the $\mathrm{D} / \mathrm{H}$ ratio will provide us useful information on the history of the planetary atmosphere.

Our knowledge about the Martian atmosphere has been enriched by remote sensing from fly-by or orbiting spacecraft of USA and USSR. The structure and composition of the Martian upper atmosphere have been investigated by ultraviolet remote sensing; see Paxton and Anderson (1992). Mariner 6 and 7, which had an ultraviolet spectrometer of the Fastie-Ebert scanning monochrometer design, flew by Mars on July 31 and August 5, 1969, respectively (Pearce et al., 1971; Barth et al., 1971). The spectrometer measured the wavelength range from 190 to $430 \mathrm{~nm}$ with $2 \mathrm{~nm}$ resolution and a range from 110 to 210 $\mathrm{nm}$ with $1 \mathrm{~nm}$ resolution. Mariner 6 obtained limb data for solar zenith angles of 27 and 0 degrees, while Mariner 7 performed limb observations at 44 and 0 degree solar zenith angles. Mariner 9 was placed into a lower-inclination orbit with a period of 32.8 hours on November 13, 1971, and from 349 Earth days of operation achieved all of its

Copy right $\odot$ The Society of Geomagnetism and Earth, Planetary and Space Sciences (SGEPSS); The Seismological Society of Japan; The Volcanological Society of Japan; The Geodetic Society of Japan; The Japanese Society for Planetary Sciences. objectives. The ultraviolet spectra of the Martian airglow were obtained by the Mariner 9 ultraviolet spectrometer experiment (Barth et al., 1972). The detection and mapping of ozone were also accomplished. The HI $121.6 \mathrm{~nm}$ and OI $130.4 \mathrm{~nm}$ airglows were measured by Mars 3 and 5 orbiters launched on May 28, 1971 and July 25, 1973, respectively (Dementyeva et al., 1972; Kurt et al., 1974). Viking 1 and 2 were inserted into Mars orbits on June 19, 1976 and August 7, 1976, respectively, and had 6.4 Earth years of operation. Further Phobos 2 was inserted into a Mars orbit on January 29, 1989. Unfortunately, telemetry communication was lost on March 27, 1989. However, contributions of these spacecraft to the studies of the corona and the upper atmosphere were little, since these spacecraft had no ultraviolet spectrometers.

PLANET-B was launched on July 3, 1998 at Kagoshima Space Center (KSC) of the Institute of Space and Astronautical Science (ISAS) of Japan and named after NOZOMI. The arrival at Mars has been originally October 1999, however, it will be delayed until December 2003 due to a trouble in the propulsion system. The NOZOMI spacecraft has 14 scientific instruments to observe the surface, atmosphere, ionosphere and magnetosphere of Mars on an elliptical orbit of a periapsis of $150 \mathrm{~km}$ and an apoapsis of 15 Martian radii; see Yamamoto and Tsuruda (1998). The inclination of the NOZOMI orbit will be chosen to 170 degrees to observe the subsolar ionosphere and to keep the solar eclipse period within the allowed time. In this paper we review the scientific objectives first, focusing on observations of hydrogen and oxygen coronas, D/H ratio and airglow, and then describe the optics and the data processing of the NOZOMI ultraviolet 
imaging spectrometer (UVS) which covers the FUV and MUV range from 110 to $310 \mathrm{~nm}$. We also show initial data taken by the UVS instrument during the Earth orbiting phase and the early phase of the Mars transfer orbit.

\section{Scientific Objectives of the UVS Experiment 2.1 Hydrogen corona}

Hydrogen Lyman $\alpha$ corona around Mars was observed for the first time by ultraviolet spectrometers on Mariner 6 and 7 spacecraft. From hydrogen Lyman $\alpha$ limb profiles, Anderson and Hord (1971) showed an exospheric temperature of $350 \pm 50 \mathrm{~K}$ and an exobase density of $3 \pm$ $1 \times 10^{4} \mathrm{~cm}^{-3}$. They estimated the escape flux of atomic hydrogen as $2 \times 10^{8} \mathrm{~cm}^{-2} \mathrm{sec}^{-1}$. From similar observations by Mariner 9, Anderson (1974) obtained an altitude profile of hydrogen down to $80 \mathrm{~km}$ where Lyman $\alpha$ photon absorption by $\mathrm{CO}_{2}$ occurs. In addition, the $\mathrm{H}_{2}$ altitude profile was calculated with the $\mathrm{CO}_{2}^{+}$data under a photochemical-diffusion model for the Martian thermosphere. The Martian hydrogen corona was also measured from an Earth orbit by the Copernicus satellite (Levine et al., 1978). The result showed a very low exospheric temperature of $175 \pm 50 \mathrm{~K}$ during a period of low solar activity. A mass spectrometer on Viking spacecraft confirmed again the low exospheric temperature. The escape flux of hydrogen may be twice that of oxygen (McElroy, 1972; McElroy et al., 1977). Anderson (1974) reported a much smaller rate than McElroy's prediction.

Observations of hydrogen corona give us information on the densities and temperatures of the exosphere. Further, we can examine the solar wind-Martian atmosphere interaction processes from observations of the hydrogen corona, since the solar wind interacts with the corona through charge exchange reactions, ion pick-up or sputtering processes. The UVS on board NOZOMI will measure the hydrogen corona over an altitude range of $150-20000 \mathrm{~km}$ and approximate local time ranges of 9-15 LT and 21-3 LT. Nishikawa (private communication) studied intensity distribution of the Martian hydrogen corona at Lyman $\alpha$ by a Monte Carlo simulation and showed that a $100 \mathrm{~K}$ difference of the exobase temperature leads to an intensity difference of more than $500 \mathrm{R}$ at a tangential altitude of $10000 \mathrm{~km}$. The UVS can detect an intensity difference of $100 \mathrm{R}$ for the hydrogen corona with a $1 \mathrm{kR}$ intensity by integrating for a half hour, and will give us information to discuss response of the Martian atmosphere to the solar activity.

\section{$2.2 \mathrm{D} / \mathrm{H}$ ratio}

For the evolution of the atmospheres of the terrestrial planets, understanding of atmospheric escape processes is essential. Preferential escape of hydrogen to deuterium will cause an enrichment of the atmospheric abundance of deuterium over geological time. The D/H ratio of Martian upper atmosphere was obtained from the analysis of $\mathrm{H}_{2} \mathrm{O}$ and HDO absorption spectra observed by the $3.6 \mathrm{~m}$ CanadaFrance-Hawaii telescope at Mauna Kea (Owen et al., 1988). They obtained a value of $9 \pm 4 \times 10^{-4}$. The enhanced $\mathrm{D} / \mathrm{H}$ ratio by a factor of $6 \pm 3$ on Mars relative to the value on Earth may imply that substantial amount of water have been lost to space over geological time. However, these observations revealed only the average values over the planetary atmosphere. Surface features resembling massive outflow channels also provide evidence that Martian crust might have contained enough water to form a global layer $500 \mathrm{~m}$ thick or greater (Carr, 1986). The UVS will perform the first direct measurement of $\mathrm{D} / \mathrm{H}$ ratio in the Martian upper atmosphere. It is expected that a $\mathrm{D} / \mathrm{H}$ ratio of $\sim 10^{-4}$ can be detected with spatial and temporal integration of $\sim 10^{5} \mathrm{sec}$ pixels. This measurement will be useful for studies of the escape processes of hydrogen and deuterium atoms and the history of the atmosphere.

\subsection{Oxygen corona}

Analogous to the oxygen corona of Venus observed by the Pioneer Venus Orbiter (Nagy et al., 1981; Paxton and Meier, 1986), the presence of hot oxygen around Mars is expected. Calculations of hot oxygen populations at Mars were carried out by Nagy and Cravens (1988) and Ip $(1988,1990)$. They assumed that the dissociative recombination of $\mathrm{O}_{2}^{+}$is the most important reaction for producing hot oxygen. The oxygen corona can be observed by measuring the atomic oxygen line at $130.4 \mathrm{~nm}$. This line is excited by two mechanisms. The major mechanism is resonant scattering of solar photons and the other mechanism is excitation by photoelectron impact. The ultraviolet spectrometer on Mariner 9 obtained the extensive set of measurements of the Martian OI $130.4 \mathrm{~nm}$ intensity profiles. However, the purpose of the OI 130.4 nm observation on Mariner 9 was to study the composition structure in the thermosphere. Therefore, the oxygen corona above the exobase was not examined in detail probably because of the lack of sufficient sensitivity. A long term observation by the UVS will provide intensity distributions of the oxygen corona in the altitude range of $150-1000 \mathrm{~km}$ with sufficient intensity resolution for studying the non-thermal escape process of oxygen atoms. 2.4 Dayglow

Dayglow emissions observed by the UVS on board NOZOMI will give us useful information on the structure and heating processes of the Martian upper atmosphere and ionosphere. The observed brightness of the dayglow depends on (1) the solar flux, (2) the illumination and observing angle, and (3) the abundance, distribution, and temperature of its source species. Considering the effects of (1) and (2), information on (3) is derived. The UVS detects emissions between 110 and $310 \mathrm{~nm}$. Dayglow emissions observed by Mariner 9 in this wavelength region are OI 130.4 and $135.6 \mathrm{~nm}, \mathrm{CO}$ fourth positive bands, CI 156.1 and $165.7 \mathrm{~nm}, \mathrm{CO}$ Cameron bands, $\mathrm{CO}_{2}{ }^{+}$ (B-X) bands at $289 \mathrm{~nm}$ and OI $297.2 \mathrm{~nm}$.

The Mariner 9 ultraviolet spectrometer measurements of OI $130.4 \mathrm{~nm}$ emission from thermospheric atomic oxygen were modeled by Strickland et al. (1973). They concluded that the limb data were best explained by oxygen fractional abundance of $0.5-1 \%$ at the 1.2 nbar pressure level. Stewart et al. (1992) used the Mars thermospheric general circulation model (MTGCM) of Bougher et al. (1990) and the Monte Carlo partial frequency redistribution multiple scattering code of Meier and Lee (1982) to simulate the OI $130.4 \mathrm{~nm}$ emission measured by 
Mariner 9. They found that the decline in atomic oxygen through the daylight hours predicted by the MTGCM cannot be reconciled with the excess afternoon brightness seen in the data. Stewart et al. (1992) concluded that solar forcing alone cannot account for the observed characteristics of the Martian thermosphere and that wave and tidal effects may profoundly affect the structure, winds, and composition.

Roughly speaking, the tangential point of field-of-view of the UVS moves slowly between $9 \mathrm{LT}$ and $15 \mathrm{LT}$ and between $21 \mathrm{LT}$ and $3 \mathrm{LT}$ with a period of conjunction between Mars and the Earth. Therefore, limb observation of the OI $130.4 \mathrm{~nm}$ dayglow emission by the UVS does not extend to an entire local time region. It might be difficult to distinguish the effect of migrating tide from that of nonmigrating tide in the dayglow data, however, the data obtained by the UVS will give us a hint on this subject.

The CO fourth positive bands ( $\mathrm{A}^{1} \Pi-\mathrm{X}^{1} \Sigma^{+}$transition) extend from 128 to $280 \mathrm{~nm}$. Fox and Dalgarno (1979) have evaluated the sources for the $\mathrm{CO}$ fourth positive bands in the Martian atmosphere showing that photodissociation and electron impact dissociation of $\mathrm{CO}_{2}$ may be important excitation mechanisms. Using the Mariner 6 and 7 data, Thomas (1971) determined a lower limit on $n$ (CO, 160 $\mathrm{km})>7.4 \times 10^{6} \mathrm{~cm}^{-3}$ and $n(\mathrm{CO}, 170 \mathrm{~km})>9.4 \times 10^{6}$ $\mathrm{cm}^{-3}$. Mumma et al. $(1975)$ reported $n(\mathrm{CO}, 150 \mathrm{~km})=1.5$ $\times 10^{8} \mathrm{~cm}^{-3}$. These results are very close to Viking NMS observation (Nier and McElroy, 1977). Atomic carbon is a minor constituent in the atmosphere of Mars, but there are two FUV transitions: the CI 156.1 and $165.7 \mathrm{~nm}$ multiplets.

The atomic carbon distribution in the atmosphere of Mars has been studied by McElroy and McConnell (1971) and Krasnopolsky (1983). Integrated volume emission rates in the CI 133.9, 156.1, and $165.7 \mathrm{~nm}$ lines were calculated by Fox and Dalgarno (1979) for the electron impact dissociative excitation source.

The Cameron bands ( $\mathrm{a}^{3} \Pi-\mathrm{X}^{1} \Sigma^{+}$transition) of CO appear in the spectrum between 190 and $270 \mathrm{~nm}$. These Cameron bands are produced by (1) the photodissociation of $\mathrm{CO}_{2}$ by solar EUV radiation, (2) the electron impact dissociation of $\mathrm{CO}_{2}$ by photoelectrons, and (3) the dissociative recombination of $\mathrm{CO}_{2}^{+}$(Fox and Dalgarno, 1979). The intensity variation of the Cameron band as a function of altitude was used to determine the structure of the neutral atmosphere above $120 \mathrm{~km}$ and from the scale height, the temperature of the thermosphere was estimated (Stewart et al., 1972).

The $\mathrm{CO}_{2}^{+}\left(\mathrm{B}^{2} \Sigma_{\mathrm{a}}^{+}-\mathrm{X}^{2} \Pi_{\mathrm{g}}\right.$ transition $)$ band at $289 \mathrm{~nm}$ variations of this band is produced by the photoionization of $\mathrm{CO}_{2}$. The intensity is used to estimate the rate of ionization of the Martian ionosphere as a function of altitude (Fox and Dalgarno, 1979).

\subsection{Nightglow and aurora}

Electron precipitation into the nightside atmosphere produces optical emissions. Usually atmospheric emissions caused by precipitating particles of much greater than thermal energies are called aurora. Aurora and airglow in the Venusian and Martian atmospheres are reviewed by Fox (1992). Emissions of atomic oxygen at 130.4 and
$135.6 \mathrm{~nm}$ were detected by the Pioneer Venus Orbiter ultraviolet spectrometer in images of the nightside of Venus (Phillips et al., 1986). Intensities of the $130.4 \mathrm{~nm}$ emission are typically about $10 \mathrm{R}$, but excursions to 100 $\mathrm{R}$ were recorded. The model calculations of Fox and Stewart (1991) presented the upper and lower limits to the magnitude of the electron flux necessary to produce the observed intensities. For the electron fluxes measured by the PVORPA, they estimated the intensities of OI 130.4 and $135.6 \mathrm{~nm}$ and $\mathrm{CO}$ Cameron band emissions to be 24, 58 , and $69 \mathrm{R}$, respectively.

The only published data on the nightside emissions of Mars is that of Krasnopolsky and Krysko (1976). They examined the data from a spectrometer on board Mars 5 and indicated the upper limit of nightglow emissions of $\sim 50 \mathrm{R}$ in the wavelength region 300-800 nm. Haider et al. (1992) calculated electron impact ionization and excitation in the nightside atmosphere of Mars using the electron fluxes measured by the HARP instrument on board PHOBOS 2. The calculated zenith column emission rates of the OI 557.7 and $630.0 \mathrm{~nm}$ and CO Cameron band emissions due to impact of plasma sheet electrons and dissociative recombination mechanisms, are 57, 19, and $87 \mathrm{R}$, respectively.

As mentioned above, the observations of airglow emissions on the nightside of Mars were carried out only in the near ultraviolet (NUV) and visible range between 300 and $800 \mathrm{~nm}$ in the past, and observations in the FUV and MUV range have never been performed. It is expected that observations of the nightside hemisphere by the UVS instrument on board NOZOMI from a distance of several Martian radii will answer the questions on the nightside airglow and auroral emissions in this spectral range.

\section{Ultraviolet Imaging Spectrometer (UVS) 3.1 Overview of UVS}

The UVS instrument is composed of two sensors, a grating spectrometer (UVS-G) and an absorption cell photometer (UVS-P), and an electronic unit (UVS-E). Plate 1 shows a view of the UVS-G and UVS-P. The UVS$E$ unit is installed in the electronic unit of the MPM subsystem, which consists of a fluxgate magnetometer (MGF), a probe for electron temperature (PET), an extendable mast (MST) and the UVS. A block diagram of the UVS instrument is shown in Fig. 1, and its specifications are listed in Table 1. All components of the UVS were adequately designed so as to be as small and light as possible with minimal degradation of optical performance in order to suit severe weight and power reduction requirements of the NOZOMI spacecraft. The total weights of UVS-G and UVS-P are $1.77 \mathrm{~kg}$ and $0.83 \mathrm{~kg}$, respectively, while the maximum power consumption of the UVS is $15.8 \mathrm{~W}$. A common CPU (SI-CPU) controls the MPM subsystem including the UVS.

\subsection{UVS-G}

The UVS-G is a flat-field type spectrometer operating in the wavelength range between $110 \mathrm{~nm}$ and $310 \mathrm{~nm}$ with a spectral resolution of 2-3 nm. The optics consists of an off-axis parabolic mirror, a slit, a concave diffraction grating, two dichroic folding mirrors, and two types of 


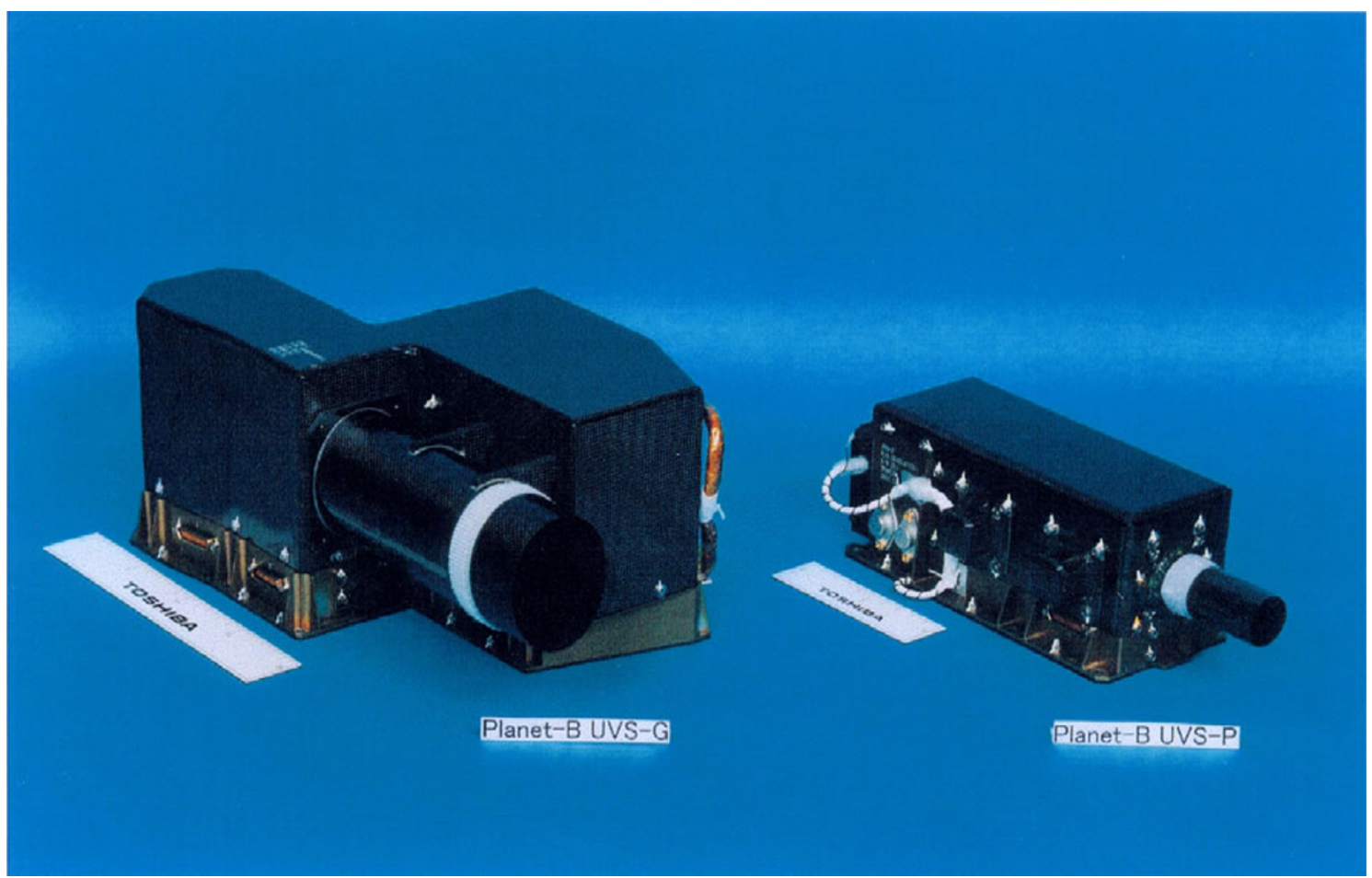

Plate 1. A view of UVS-G and UVS-P.

(a)

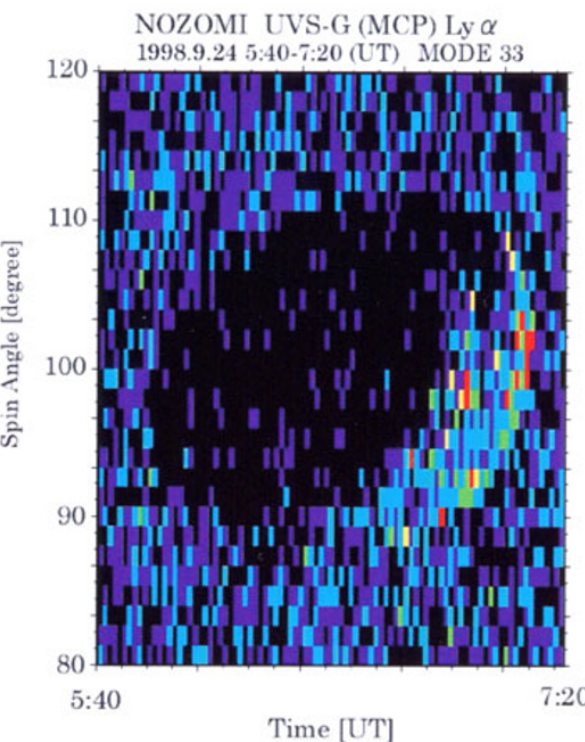

(b)

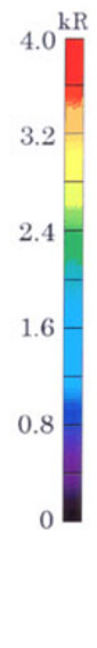

)

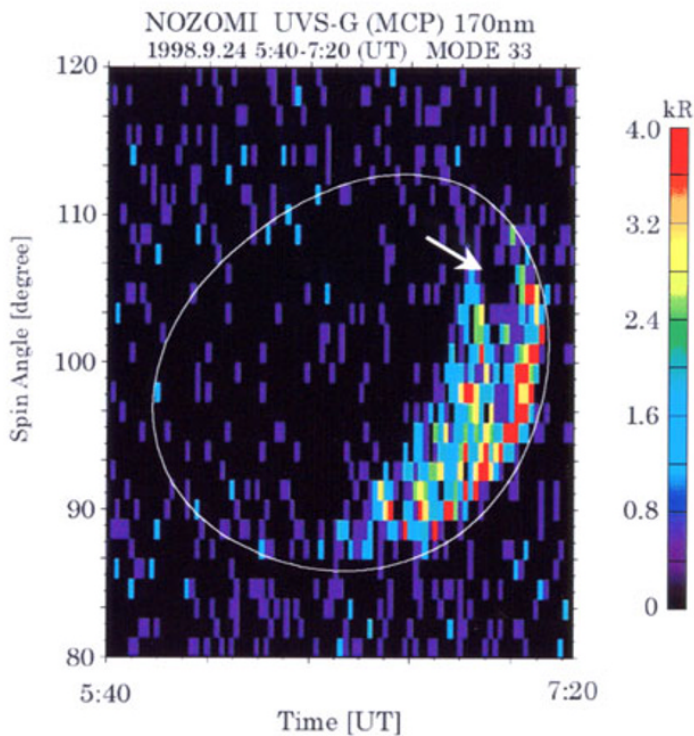

Plate 2. Images of the moon taken by the UVS-G during the first lunar swing-by on September 24,1998 at wavelengths of (a) Lyman $\alpha$ (121.6 $\mathrm{nm}$ ) and (b) $170 \mathrm{~nm}$. The lunar image, of which approximate outline is depicted by a thin white line in the right image, is distorted because of orbital motion of the spacecraft during the observation period from 05:40 to 07:20 UT. In the Lyman $\alpha$ image the dark nightside hemisphere of the moon stands out against the background emission due to the interplanetary Lyman $\alpha$ with intensity of about 500 R. On the other hand, the interplanetary component is not seen in the image at $170 \mathrm{~nm}$. Sea of Crises, which is indicated by an arrow in the right image, exhibits extremely low albedo at these two wavelengths.

photodetectors as schematically shown in Fig. 2, The field-of-view is perpendicular to the spin axis of the spacecraft. Ultraviolet emissions incident into the aperture of the UVS-G are collected by the objective mirror with a $50 \mathrm{~mm}$ diameter and a $100 \mathrm{~mm}$ focal length. This mirror is made of beryllium and plated with nickel to satisfy requirements for the weight reduction and optical performance. The mount and screws of the mirror assembly are also made of beryllium. The entrance slit with a 0.15 $\mathrm{mm} \times 0.5 \mathrm{~mm}$ rectangular aperture limits the instantaneous field-of-view of the instrument to $0.09^{\circ}$ in a plane perpendicular to the spin axis and to $0.29^{\circ}$ in a plane 


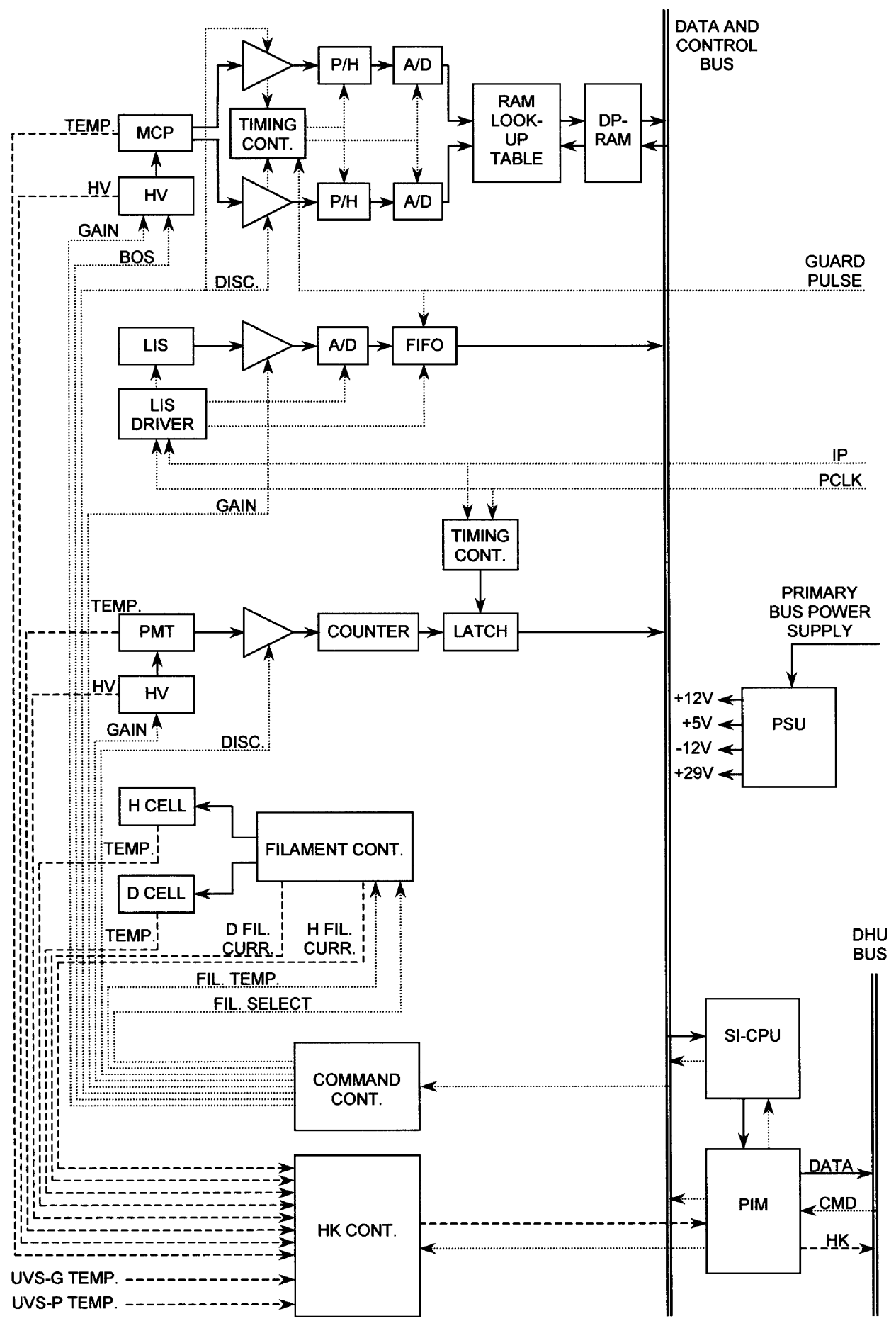

Fig. 1. Block diagram of the UVS instrument. Data and power flow, command and control signal flow, and HK data flow are indicated by solid, dotted and dashed lines, respectively.

including the spin axis. Incident ultraviolet emissions are dispersed by the concave diffraction grating with a $50 \mathrm{~mm}$ diameter and focused on the ultraviolet detectors. The first order spectrum in the wavelength range from 110 to $200 \mathrm{~nm}$ is detected by a micro-channel plate (MCP) with a CsI photocathode and strip anodes. The MCP operates in a photon counting mode. The pattern of the strip anodes is shown in Fig. 3. A position of an incident photon is determined from a ratio of charge pulse heights collected by two strip anodes as described later.
The second order spectrum in the wavelength range from 200 to $310 \mathrm{~nm}$ is detected by a linear image sensor (LIS) which is a linear array of 512 photodiodes. Signals from every eight successive elements of the LIS are summed to generate 64 spectral signals. Note that the spectral resolution is determined by dispersion of the grating, though the detector has much higher spatial resolution. The ray path of the second order spectrum is folded by two dichroic mirrors placed in front of the LIS to avoid mechanical interference between the two detectors 

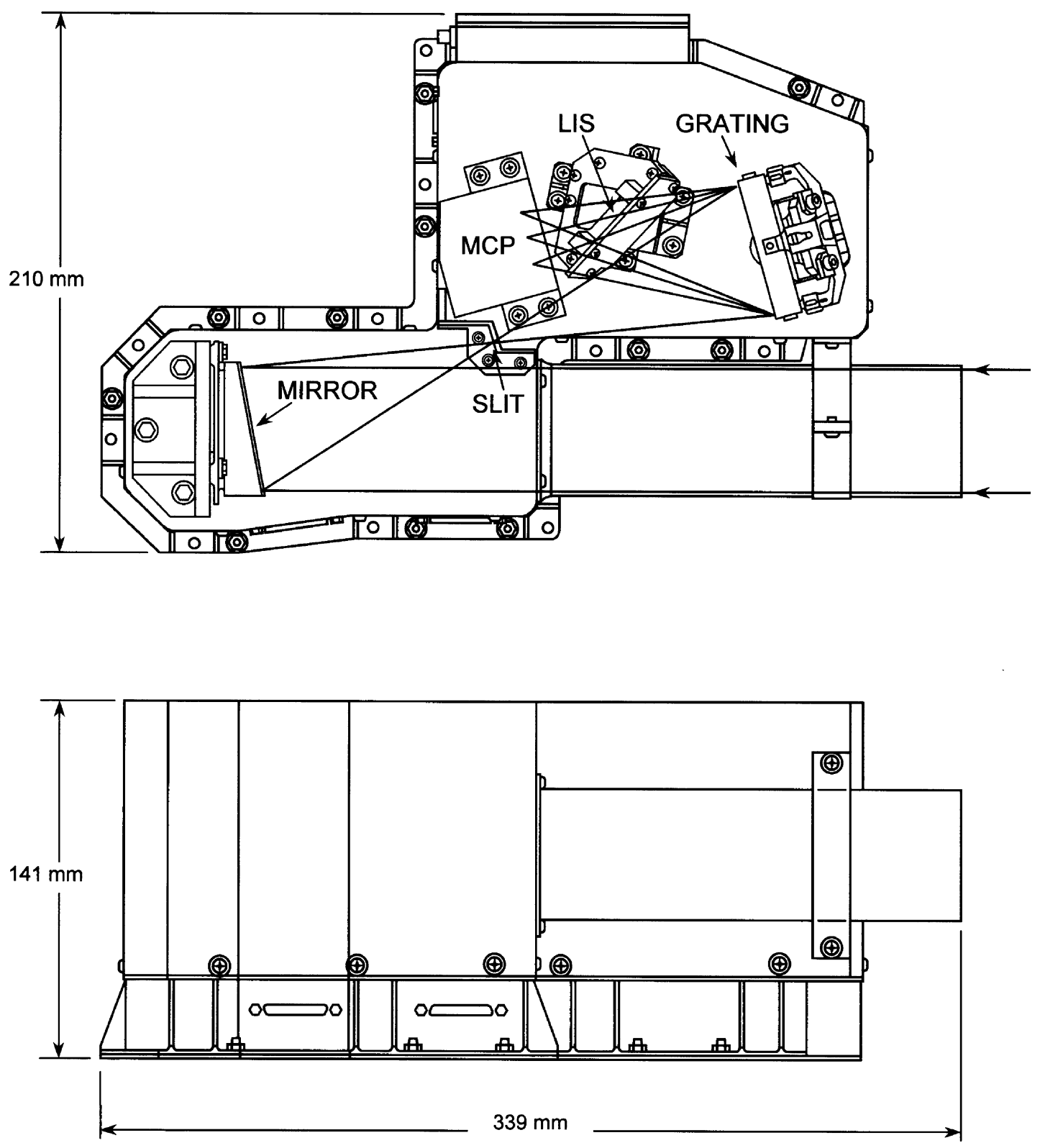

Fig. 2. Schematic of the UVS-G instrument.

and remove the first order spectrum from 400 to $620 \mathrm{~nm}$ that overlaps on the second order spectrum. The LIS also functions as a bright object sensor which detects the Martian bright disk and shuts down the high-voltage supplied to the MCP to avoid permanent damage of the MCP due to excess photocurrent. The phase clock (PCLK) divides a spin period (nominally $8 \mathrm{sec}$ ) into 256 time intervals for timing of data sampling. The spatial resolution of this instrument is, therefore, $1.41^{\circ} \times 0.29^{\circ}$. Although the UVS-G instrument instantaneously points to a certain direction with this field-of-view, spatial distributions of emissions are measured by using the spin and orbital motion of the NOZOMI spacecraft as shown in Fig. 4. A baffle and field stops suppress stray light mainly due to solar radiation reflected on the surface of NOZOMI and from the bright disk of Mars during limb measurements. It was confirmed during the performance test in the laboratory that the stray light level at $1.41^{\circ}$ (=FOV of UVS-G) apart from a bright light source is less than $10^{-3}$.

The absolute sensitivity of the UVS-G in the wavelength region of 110-200 $\mathrm{nm}$ was calibrated using a vacuum facility at National Institute of Polar Research, Japan. Ultraviolet capillary lamps which contain gaseous hydrogen, xenon, krypton and mercury, respectively emitting characteristic spectral lines were used as a light source. Emission lines of Kr $123.6 \mathrm{~nm}$, Xe $147.6 \mathrm{~nm}$ and $\mathrm{Hg} 185.0 \mathrm{~nm}$ were selected by bandpass filters and diffused by a $\mathrm{MgF}_{2}$ diffuser plate. Figure 5 shows spectra of these light sources measured by the UVS-G and normalized at their peaks. Absolute intensities of the diffused ultraviolet light were measured by a standard photodiode which has a quantum efficiency of $\sim 1$ in this wavelength region (Gullikson et al., 1996). Sensitivities derived from the experiment are listed in Table 2. Uncertainty in the absolute 
Table 1. Specifications of the UVS instrument.

\begin{tabular}{|c|c|}
\hline Item & Characteristic \\
\hline \multicolumn{2}{|l|}{ UVS-G } \\
\hline Wavelength region & $110-310[\mathrm{~nm}]$ \\
\hline \multirow[t]{2}{*}{ Spectral resolution } & $2.7[\mathrm{~nm}] @ 110-200[\mathrm{~nm}]$ \\
\hline & $3.4[\mathrm{~nm}] @ 200-310[\mathrm{~nm}]$ \\
\hline \multirow[t]{2}{*}{ Field-of-view } & $0.29^{\circ}$ (in a plane including the spin axis) \\
\hline & $0.09^{\circ}$ (in a plane perpendicular to the spin axis) \\
\hline \multirow[t]{2}{*}{ Spatial resolution } & $0.29^{\circ}$ (in a plane including the spin axis) \\
\hline & $1.41^{\circ}$ (in a plane perpendicular to the spin axis) \\
\hline Detector & Micro-channel plate (MCP) with strip anodes and MOS linear image sensor (LIS) \\
\hline Maximum count rate of MCP & $2.2 \times 10^{4}[\mathrm{cps}]$ \\
\hline Dynamic range of LIS & $10^{5}-10^{9}[$ Photons/s/Pixel $]$ \\
\hline Weight & $1.77[\mathrm{~kg}]$ \\
\hline \multicolumn{2}{|l|}{ UVS-P } \\
\hline \multirow[t]{2}{*}{ Wavelength } & $121.567[\mathrm{~nm}](\mathrm{H}$ Lyman $\alpha)$ \\
\hline & $121.534[\mathrm{~nm}](\mathrm{D} \operatorname{Lyman} \alpha)$ \\
\hline \multirow[t]{2}{*}{ Field-of-view } & $3.0^{\circ}$ (in a plane including the spin axis) \\
\hline & $0.5^{\circ}$ (in a plane perpendicular to the spin axis) \\
\hline \multirow[t]{2}{*}{ Spatial resolution } & $3.0^{\circ}$ (in a plane including the spin axis) \\
\hline & $1.41^{\circ}$ (in a plane perpendicular to the spin axis) \\
\hline Detector & Side-on type solar blind photomultiplier tube \\
\hline Weight & $0.83[\mathrm{~kg}]$ \\
\hline Power (all of UVS) & $15.8[\mathrm{~W}]$ (maximum) \\
\hline
\end{tabular}

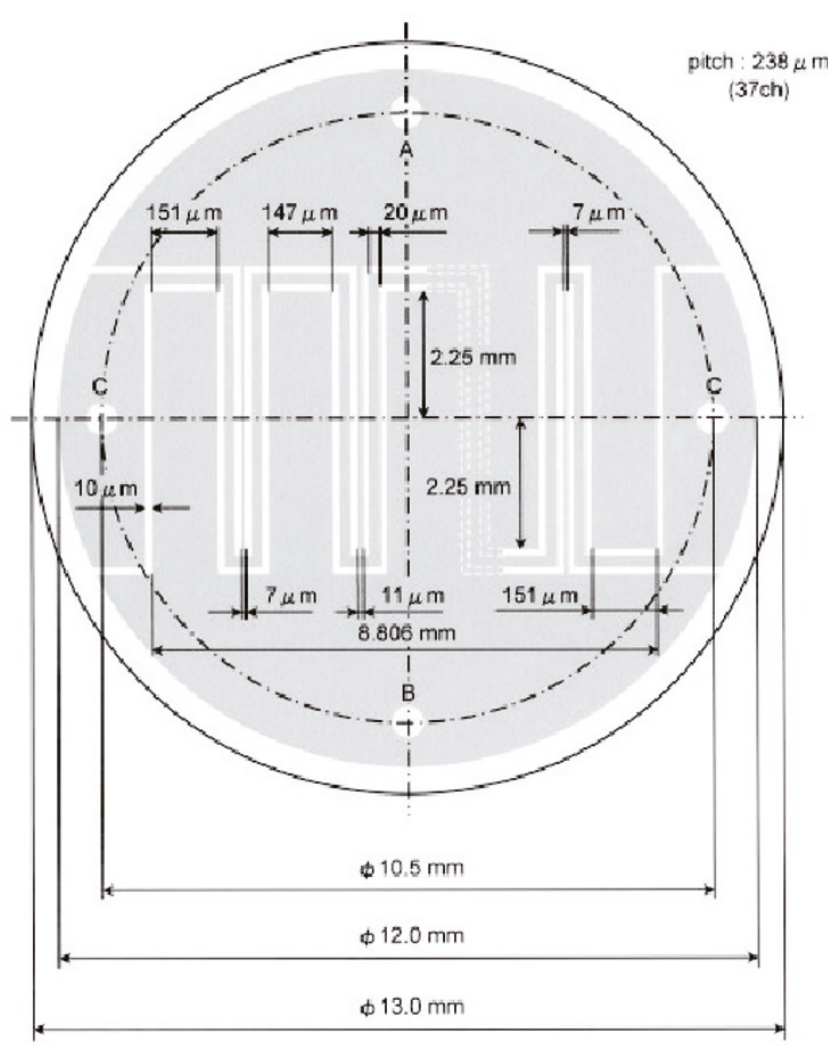

Fig. 3. Pattern of strip anodes attached on an MCP. A, B, and C indicate electrical pins for anodes $\mathrm{A}, \mathrm{B}$, and $\mathrm{C}$, respectively. Charges that fall on anodes $\mathrm{A}$ and $\mathrm{B}$ are fed into amplifiers for detection, while anode $\mathrm{C}$ is connected to the ground.

sensitivity of the UVS comes mainly from uncertainty in the quantum efficiency of the photodiode, which is about $15 \%$. On the other hand absolute sensitivity in the wavelength region of $200-310 \mathrm{~nm}$ is determined by

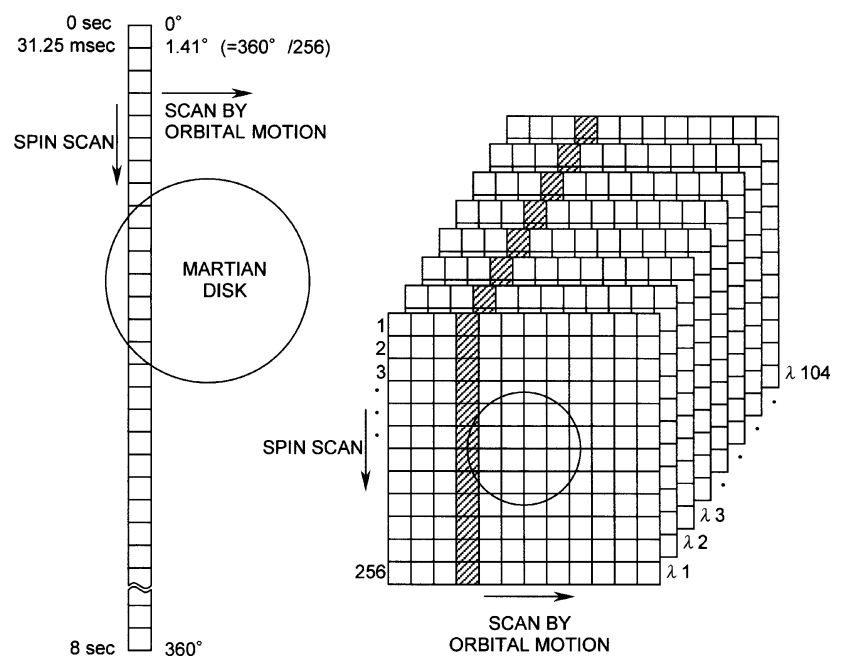

Fig. 4. Imaging method of the UVS using the spin and orbital motion of the spacecraft. The right hand figure shows how the UVS builds up a hyperspectral image cube: each point in the image has a third spectral dimension.

calculation using the transmittance of each optical component and the nominal sensitivity of the LIS, because we did not have a good standard in this wavelength region. The spectral region, spectral resolution and field-of-view of the UVS-G instrument were also confirmed by using these line emissions shown in Fig. 5 for the MCP and emission lines from a mercury-xenon lamp for the LIS.

\subsection{UVS-P}

The UVS-P consists of two glass-type absorption cells, a bandpass filter, a slit and a side-on type photomultiplier tube (PMT), as shown in Fig. 6. Kawahara et al. (1997) describes new glass-type absorption cells developed for this mission in detail. Each absorption cell has a cylindrical shape with $25 \mathrm{~mm}$ diameter and $60 \mathrm{~mm}$ length and $\mathrm{MgF}_{2}$ 


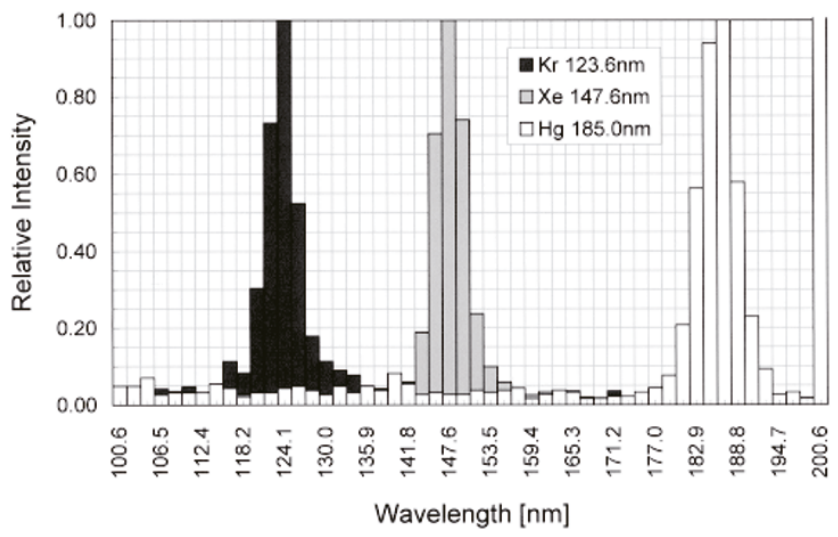

Fig. 5. Spectra of calibration light sources measured by UVS-G. These spectra are normalized at their peaks. The wavelength range of UVS$\mathrm{G}$ was calibrated by positions of these emission lines, $\mathrm{Kr} 123.6 \mathrm{~nm}$, $\mathrm{Xe} 147.6 \mathrm{~nm}$, and $\mathrm{Hg} 185.0 \mathrm{~nm}$. Absolute sensitivity was determined from count rates of these spectral lines and the absolute intensity of the light sources.

Table 2. Sensitivities of UVS-G and UVS-P.

\begin{tabular}{lccccc}
\hline Sensor & \multicolumn{4}{c}{ UVS-G } & UVS-P \\
\cline { 2 - 5 } Detector & MCP & MCP & MCP & LIS & PMT \\
\hline$\lambda[\mathrm{nm}]$ & 124 & 148 & 185 & 250 & 122 \\
Sensitivity & 16 & 110 & 39 & 11 & 2.8 \\
Unit & $\mathrm{cps} / \mathrm{kR}$ & $\mathrm{cps} / \mathrm{kR}$ & $\mathrm{cps} / \mathrm{kR}$ & $\mathrm{cps} /(\mathrm{MR} / \mathrm{nm})$ & $\mathrm{cps} / \mathrm{kR}$ \\
\hline
\end{tabular}

windows are attached at both ends of the cell. $\mathrm{MgF}_{2}$ is only optical material available at the wavelength of Lyman $\alpha$ without deliquescence. Light is collected by a $\mathrm{MgF}_{2}$ lens which serves the first window of the first (hydrogen) absorption cell. The bandpass filter has a bandwidth of 8.8 $\mathrm{nm}$ and a peak transmittance of $9.5 \%$ and is used to select hydrogen and deuterium Lyman $\alpha$ emissions from the background continuum. Pure hydrogen or deuterium gas is filled in the absorption cells at pressure of 3 Torr. Hydrogen or deuterium molecules are thermally dissociated into atoms by turning on one of four tungsten filaments equipped in each absorption cell. Hydrogen and deuterium atoms absorb $\mathrm{H}$ and $\mathrm{D}$ Lyman $\alpha$ emissions at $121.567 \mathrm{~nm}$ and $121.534 \mathrm{~nm}$, respectively. The PMT has a solar-blind photocathode made of CsI and placed at the focus of the lens. Turning-on sequence and temperature of filaments are controlled by software of the SI-CPU. The instantaneous field-of-view of UVS-P is $0.5^{\circ} \times 3.0^{\circ}$ and the spatial resolution determined by data sampling rate is $1.4^{\circ} \times 3.0^{\circ}$. The measurement of the spatial distribution of Lyman $\alpha$ emissions is also accomplished by using the spin and orbital motion of the spacecraft as the UVS-G.

Absolute sensitivity of the UVS-P was also calibrated by the same method as the UVS-G using a hydrogen capillary lamp. The result is shown in the last column of Table 2. It was also confirmed that the stray light level at $1.41^{\circ}$ (=FOV of UVS-P) apart from a bright light source is less than $10^{-3}$.
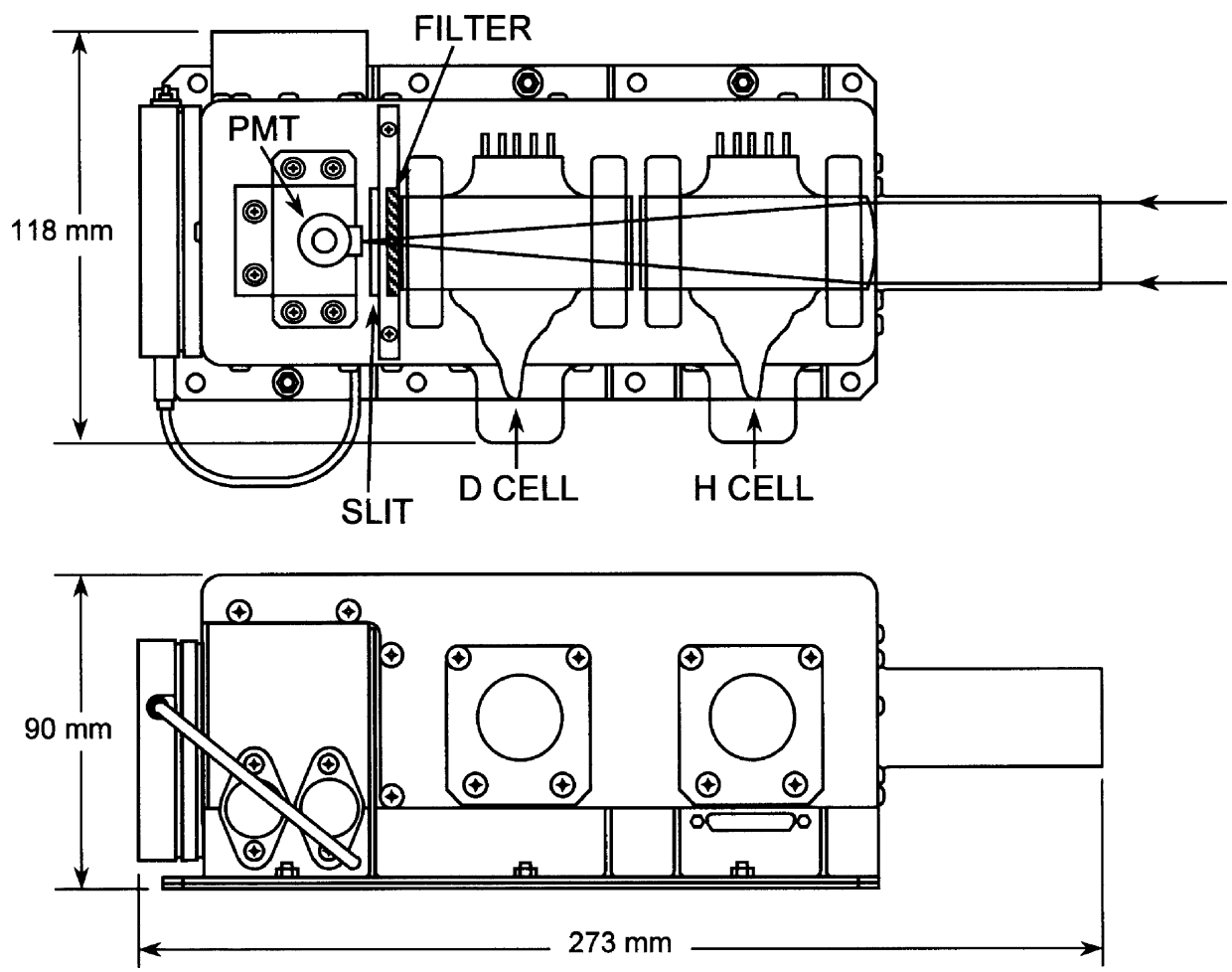

Fig. 6. Schematic of the UVS-P instrument. 
Absorption profiles of the absorption cells were precisely measured with a high resolution vacuum ultraviolet spectrometer with a wavelength resolution of $0.6 \times 10^{-4}$ $\mathrm{nm}$ at Photon Factory in the High Energy Accelerator Research Organization, Japan (Taguchi et al., 1997). Figure 7 shows measured absorption profiles of a hydrogen absorption cell equivalent to that installed in the UVS. The optical thicknesses at the center of absorption line and gas temperatures were derived by fitting Gausian functions to the measured absorption profiles and the result is listed in Table 3. It is noted that the optical thickness and gas temperature vary with the filament temperature proportional to the filament power. For the UVS-P one of four preset filament temperatures can be selected by a command.

\subsection{UVS-E}

The high-voltage power supply for the MCP is toggled by a discrete command (DC) and also signals from the BOS. A photon incident into the MCP generates charge pulses in A and B of the strip anodes shown in Fig. 3. As inferred from the anode pattern the pulse heights, $\mathrm{H}_{\mathrm{A}}$ and $\mathrm{H}_{\mathrm{B}}$, are proportional to the distance from the position where a photon enters the MCP to either edge of the strip anodes. The relative position $X(=0 \sim 1)$ of the incident

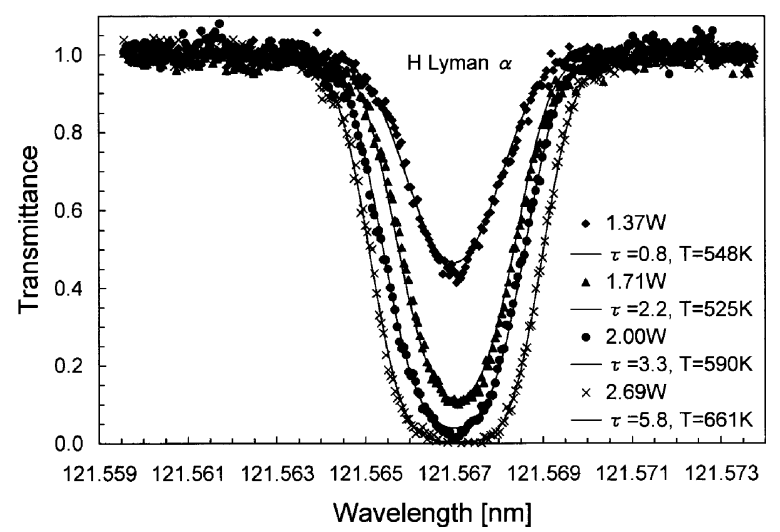

Fig. 7. Absorption profiles of a hydrogen absorption cell equivalent to that installed in the UVS. The absorption cell of which absorption profiles were measured has two flat windows that can be installed in the optical path of the spectrometer, while the absorption cell installed in the UVS-P has a plano-convex lens as one of the windows. The optical thicknesses at the center of absorption line and the gas temperatures were derived by fitting Gausian functions to the measured absorption profiles and the obtained values are listed in Table 3 . photon on the strip anodes is calculated from the relation $X=\mathrm{H}_{\mathrm{A}} /\left(\mathrm{H}_{\mathrm{A}}+\mathrm{H}_{\mathrm{B}}\right)$. The position is determined by referring to a look-up table in a RAM with 16-bit resolution and stored in one of two dual-port RAMs. While one of the dual-port RAMs accepts data for storage, the other is ready to be read by the SI-CPU. A flag indicates which dual-port RAM is ready for reading. The high-voltage level of the MCP, the gain of the pre-amplifier, the level of the BOS output and the discrimination level are set by a block command (BC) and stored in the HK data. Charges induced by incident photons in each element of the LIS are sequentially read out, amplified, digitized and stored in a FIFO memory. Timing of reading-out is triggered by a PCLK pulse from AOCE. A spectrum contains 104 spectral intensity data at most: 52 from the MCP and 52 from the LIS.

The PMT used in the UVS-P is operated in a photon counting mode. Current pulses from the PMT are amplified and shaped. A current pulse corresponding to an incident photon is discriminated from noise pulses which have relatively low pulse heights compared with the signal pulses. Arrival of the pulses is counted by a non-reset counter, the value of which count is latched at every PCLK pulse and read by the SI-CPU. The number of turned-on filaments, the filament temperature, the highvoltage level applied to the PMT, the gain of the preamplifier and the discrimination level are set by a BC and can be monitored in the HK data.

All scientific data are allocated to the memory space of the SI-CPU, while HK status, HK data, I/O flags, DC and $\mathrm{BC}$ are allocated to the $\mathrm{I} / \mathrm{O}$ space. An interrupt pulse is generated at the start of each spin referencing the IP pulse from AOCE. This pulse is sent off to INT-7 of the SI-CPU. A data ready signal of TCLK2 interrupts the SI-CPU, which then reads the data. The HK status and HK data are renewed for every $1 / 16$ of the spin period.

Table 3. Optical thicknesses and gas temperatures of absorption cells.

\begin{tabular}{crrrrr}
\hline Temperature select & \multicolumn{2}{c}{ H Cell } & & \multicolumn{2}{c}{ D Cell } \\
\cline { 2 - 3 } \cline { 5 - 6 } & \multicolumn{1}{c}{$\tau$} & $T[\mathrm{~K}]$ & & $\tau$ & $T[\mathrm{~K}]$ \\
\hline 0 & 3.3 & 590 & & 2.5 & 770 \\
1 & 4.7 & 630 & & 3.4 & 830 \\
2 & 5.9 & 660 & & 4.0 & 880 \\
3 & 10.0 & 760 & & 6.5 & 1070 \\
\hline
\end{tabular}

Table 4. UVS observation mode.

\begin{tabular}{clrr}
\hline \multirow{2}{*}{$\begin{array}{c}\text { Observation } \\
\text { mode number }\end{array}$} & \multicolumn{1}{c}{ Objects } & \multicolumn{2}{c}{$\begin{array}{c}\text { Number of data } \\
\text { in a spectrum }\end{array}$} \\
\cline { 3 - 4 } & & MCP & LIS \\
\hline 0 & Ozone, Dust, Dayglow & 0 & 52 \\
1 & Corona, Aurora & 13 & 0 \\
2 & Corona, Aurora, Dayglow & 52 & 0 \\
3 & Corona, Aurora, Dayglow, Ozone, Dust, Calibration & 52 & 52 \\
\hline
\end{tabular}




\subsection{Operation of UVS}

The UVS is operated mainly in three operation modes of the NOZOMI spacecraft for Mars observations: a standard observation mode, a periapsis mode and a UVS-XUV mode. The number of mission packets occupied by UVS data and the available telemetry bit rate are different in these modes. Scientific data taken by the UVS are arranged in mission packets according to four observation modes and eight observation sub-modes as shown in Tables 4 and 5. The observation modes determine the operation of the two photodetectors of the UVS-G instrument and determine the format of the data taken by them, while the observation sub-modes fix the turning-on sequence of filaments of the absorption cells. UVS data are co-added as synchronized

Table 5. UVS observation sub-mode.

\begin{tabular}{|c|c|c|c|c|c|c|c|}
\hline \multirow{2}{*}{$\begin{array}{l}\text { Sub-mode } \\
\text { number }\end{array}$} & \multirow[t]{2}{*}{ Objects } & \multirow{2}{*}{$\begin{array}{c}\text { Number of } \\
\text { data }\end{array}$} & \multirow{2}{*}{$\begin{array}{c}\text { Cell control sequence } \\
\text { number }\end{array}$} & \multicolumn{2}{|c|}{ H Cell } & \multicolumn{2}{|c|}{ D Cell } \\
\hline & & & & Power & Temp. & Power & Temp. \\
\hline 0 & - & 0 & - & $\mathrm{OFF}$ & - & $\mathrm{OFF}$ & - \\
\hline 1 & Hydrogen & 1 & 0 & ON & $T_{X}$ & OFF & - \\
\hline 2 & Deuterium & 1 & 0 & $\mathrm{ON}$ & $T_{3}$ & ON & $T_{X}$ \\
\hline \multirow[t]{2}{*}{3} & Hydrogen & 2 & 0 & $\mathrm{ON}$ & $T_{X}$ & OFF & - \\
\hline & & & 1 & $\mathrm{OFF}$ & - & $\mathrm{OFF}$ & - \\
\hline \multirow[t]{2}{*}{4} & Deuterium & 2 & 0 & $\mathrm{ON}$ & $T_{3}$ & OFF & - \\
\hline & & & 1 & $\mathrm{ON}$ & $T_{3}$ & $\mathrm{ON}$ & $T_{X}$ \\
\hline \multirow[t]{4}{*}{5} & Hydrogen & 4 & 0 & OFF & - & OFF & - \\
\hline & & & 1 & $\mathrm{ON}$ & $T_{0}$ or $T_{1}$ & OFF & - \\
\hline & & & 2 & $\mathrm{ON}$ & $T_{1}$ or $T_{2}$ & OFF & - \\
\hline & & & 3 & $\mathrm{ON}$ & $T_{2}$ or $T_{3}$ & OFF & - \\
\hline \multirow[t]{4}{*}{6} & Deuterium & 4 & 0 & $\mathrm{ON}$ & $T_{3}$ & $\mathrm{OFF}$ & - \\
\hline & & & 1 & $\mathrm{ON}$ & $T_{3}$ & $\mathrm{ON}$ & $T_{0}$ or $T_{1}$ \\
\hline & & & 2 & $\mathrm{ON}$ & $T_{3}$ & ON & $T_{1}$ or $T_{2}$ \\
\hline & & & 3 & ON & $T_{3}$ & $\mathrm{ON}$ & $T_{2}$ or $T_{3}$ \\
\hline \multirow[t]{4}{*}{7} & Hydrogen\&Deuterium & 4 & 0 & OFF & - & OFF & - \\
\hline & & & 1 & $\mathrm{ON}$ & $T_{X}$ & OFF & - \\
\hline & & & 2 & $\mathrm{ON}$ & $T_{3}$ & ON & $T_{X}$ \\
\hline & & & 3 & $\mathrm{ON}$ & $T_{3}$ & ON & $T_{X}$ \\
\hline
\end{tabular}

$T_{X}$ means one of four temperature levels $T_{0}, T_{1}, T_{2}$, and $T_{3}$.

Table 6. Number of spins and approximate time for data acquisition.

\begin{tabular}{|c|c|c|c|c|c|c|c|c|c|c|c|}
\hline \multicolumn{4}{|c|}{ Format and bit rate } & \multicolumn{8}{|c|}{ UVS observation mode } \\
\hline \multirow[t]{2}{*}{ OBS-P } & \multirow[t]{2}{*}{ OBS-S } & \multirow[t]{2}{*}{ UVS/XUV } & \multirow[t]{2}{*}{ MIC WFC-M MDC } & \multicolumn{2}{|c|}{0} & \multicolumn{2}{|c|}{1} & \multicolumn{2}{|c|}{2} & \multicolumn{2}{|c|}{3} \\
\hline & & & & Spins & Time & Spins & Time & Spins & Time & Spins & Time \\
\hline- & - & $64 \mathrm{k}$ & - & 1 & $8 \mathrm{~s}$ & 1 & $8 \mathrm{~s}$ & 1 & $8 \mathrm{~s}$ & 2 & $16 \mathrm{~s}$ \\
\hline- & - & $32 \mathrm{k}$ & - & 2 & $16 \mathrm{~s}$ & 1 & $8 \mathrm{~s}$ & 2 & $16 \mathrm{~s}$ & 4 & $32 \mathrm{~s}$ \\
\hline- & - & $16 \mathrm{k}$ & - & 4 & $32 \mathrm{~s}$ & 1 & $8 \mathrm{~s}$ & 4 & $32 \mathrm{~s}$ & 8 & $1 \mathrm{~m}$ \\
\hline $64 \mathrm{k}$ & $64 \mathrm{k}$ & $8 \mathrm{k}$ & - & 8 & $1 \mathrm{~m}$ & 2 & $16 \mathrm{~s}$ & 8 & $1 \mathrm{~m}$ & 16 & $2 \mathrm{~m}$ \\
\hline $32 \mathrm{k}$ & $32 \mathrm{k}$ & $4 \mathrm{k}$ & $64 \mathrm{k}$ & 16 & $2 \mathrm{~m}$ & 4 & $32 \mathrm{~s}$ & 16 & $2 \mathrm{~m}$ & 32 & $4 \mathrm{~m}$ \\
\hline $16 \mathrm{k}$ & $16 \mathrm{k}$ & $2 \mathrm{k}$ & $32 \mathrm{k}$ & 32 & $4 \mathrm{~m}$ & 8 & $1 \mathrm{~m}$ & 32 & $4 \mathrm{~m}$ & 64 & $8 \mathrm{~m}$ \\
\hline- & $8 \mathrm{k}$ & - & $16 \mathrm{k}$ & 64 & $8 \mathrm{~m}$ & 16 & $2 \mathrm{~m}$ & 64 & $8 \mathrm{~m}$ & 128 & $16 \mathrm{~m}$ \\
\hline- & $4 \mathrm{k}$ & - & $8 \mathrm{k}$ & 128 & $16 \mathrm{~m}$ & 32 & $4 \mathrm{~m}$ & 128 & $16 \mathrm{~m}$ & 256 & $32 \mathrm{~m}$ \\
\hline- & $2 \mathrm{k}$ & - & $4 \mathrm{k}$ & 256 & $32 \mathrm{~m}$ & 64 & $8 \mathrm{~m}$ & 256 & $32 \mathrm{~m}$ & 256 & $1 \mathrm{~h}$ \\
\hline- & $1 \mathrm{k}$ & - & $2 \mathrm{k}$ & 256 & $1 \mathrm{~h}$ & 128 & $16 \mathrm{~m}$ & 256 & $1 \mathrm{~h}$ & 256 & $2 \mathrm{~h}$ \\
\hline- & 512 & - & - & 256 & $2 \mathrm{~h}$ & 256 & $32 \mathrm{~m}$ & 256 & $2 \mathrm{~h}$ & 256 & $4 \mathrm{~h}$ \\
\hline- & 256 & - & - & 256 & $4 \mathrm{~h}$ & 256 & $1 \mathrm{~h}$ & 256 & $4 \mathrm{~h}$ & 256 & $8 \mathrm{~h}$ \\
\hline- & - & - & 256 & 256 & $8 \mathrm{~h}$ & 256 & $2 \mathrm{~h}$ & 256 & $8 \mathrm{~h}$ & 256 & $16 \mathrm{~h}$ \\
\hline- & 64 & - & - & - & - & - & - & - & - & - & - \\
\hline- & - & - & 64 & - & - & - & - & - & - & - & - \\
\hline
\end{tabular}


with the spin phase. The time for stacking depends on the format (operation mode) and telemetry bit rate from 1 spin period to 256 spin periods as shown in Table 6. Each mission packet (432 bytes) for UVS data contains 416 bytes of science data and a 16 byte header which includes all information necessary for the analysis of science data.

\section{Initial Observations During the Earth Orbiting and Mars Transfer Phases}

The NOZOMI spacecraft performed seven revolutions around the Earth before insertion into a Mars transfer orbit on December 20, 1998. During this period we have carried out an initial functional test of the UVS instrument and also observations of the geocorona, the interstellar wind, and the lunar surface. The initial functional test was conducted during the first two months after launch confirming that the function and health of the UVS instrument were nominal.

The first example of the UVS data taken during the Earth orbiting phase was a FUV spectrum between 110 and $200 \mathrm{~nm}$ measured by the UVS-G while NOZOMI was approaching and leaving its sixth perigee on September 20, 1998 as shown in Fig. 8. The distance between the spacecraft and the center of the Earth ranged from 7,040 $\mathrm{km}$ to $10,050 \mathrm{~km}$ during the observation period of 10:2010:50 UT. The presence of strong Lyman $\alpha$ emission at the wavelength of $121.6 \mathrm{~nm}$ originating from the geocorona is apparent. The total intensity of Lyman $\alpha$ emission reaches $2.1 \mathrm{kR}$. In Fig. 8 a spectrum taken during the Mars transfer phase is also plotted to show the background emission from interplanetary hydrogen Lyman $\alpha$. Its intensity was calculated to be about $300 \mathrm{R}$.

Another example is images of the moon shown in Plate 2. These images were obtained by the UVS-G while NOZOMI was approaching to the moon for the first lunar swing-by on September 24, 1998. The distance between the spacecraft and the center of the moon varied from $9,240 \mathrm{~km}$ at $05: 44 \mathrm{UT}$ to $6,800 \mathrm{~km}$ at $06: 33 \mathrm{UT}$. Note that the lunar images are distorted because of the orbital motion of the spacecraft during the UVS observation period. At the wavelength of Lyman $\alpha$ the dark nightside hemisphere of the moon stands out clear against the background emission from the interplanetary Lyman $\alpha$ with an intensity of about $500 \mathrm{R}$. On the other hand the background emission at $170 \mathrm{~nm}$ is as dark as the nightside hemisphere of the moon. It is interesting that Sea of Crises, which is located at the upper edge of the crescent, exhibits extremely low albedo at these two wavelengths. This suggests that the surface mineral composition, particle size or packing at Sea of Crises is quite different from the other part seen in these images. Detailed analysis of these data is now being carried out and its results will be presented in another paper.

\section{Summary}

The scientific objectives and instrumental specifications of the UVS experiment on board the NOZOMI spacecraft are described. Results from initial observations carried out during the Earth orbiting phase and the early Mars transfer phase show that the UVS instrument is functioning normally as designed. The UVS is capable of observing spatial distributions of hydrogen and oxygen coronas,

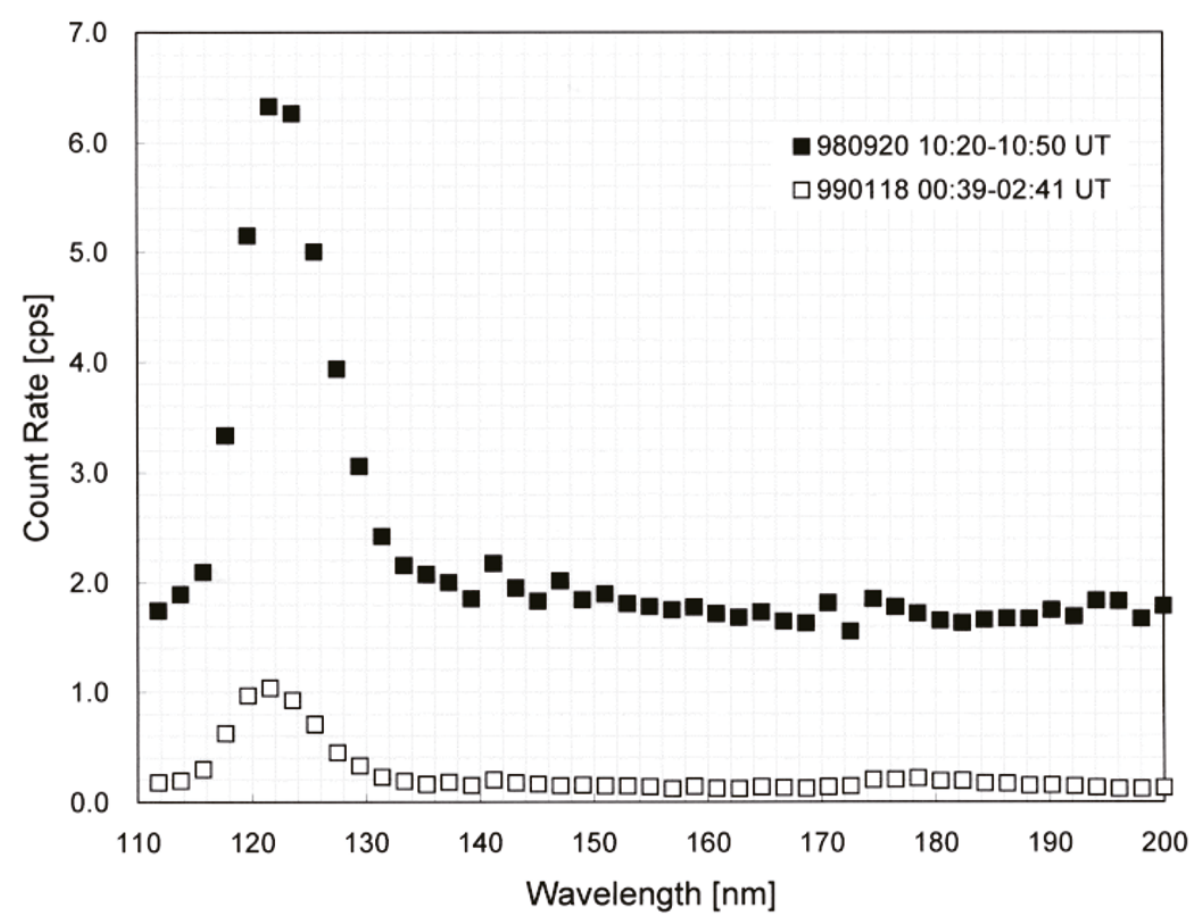

Fig. 8. An FUV spectrum measured by the UVS-G while NOZOMI was approaching to and leaving from its sixth perigee in the Earth orbiting phase on September 20, 1998 (solid squares). The spacecraft was located at the distance of 7,040-10,050 km from the center of the Earth. This spectrum includes all the data taken during the period of 10:20-10:50 UT. The strong emission at Lyman $\alpha$ mainly originates from the geocorona including a small fraction of the interplanetary component. For comparison an FUV spectrum measured on January 18, 1999 during the Mars transfer phase is plotted (open squares). The weak Lyman $\alpha$ emission in this spectrum comes from interplanetary hydrogen Lyman $\alpha$ emission. 
spectral features of $\mathrm{CO}, \mathrm{CO}_{2}^{+}$, and $\mathrm{OI}$ emission lines, and a $\mathrm{D} / \mathrm{H}$ ratio in the Martian atmosphere. Unfortunately arrival at Mars will be delayed until December 2003, however, it is expected that UVS observations will promote investigation in unsolved subjects on interaction between the Martian upper atmosphere and the solar wind and the history of the Martian atmosphere in cooperation with the other scientific instruments on board the NOZOMI spacecraft.

Acknowledgments. The authors are grateful to the late $\mathrm{T}$. Yamamoto for his leadership among the MPM team as well as the PLANET-B science team and express their thanks to S. Kanda and A. Watanabe of Toshiba Corp. for their efforts in fabricating the UVS instrument. They also thank K. Ito of the High Energy Accelerator Research Organization and A. Yamaguchi of the National Astronomical Observatory for their kind assistance in calibration experiments of the UVS. The photodetectors used in the UVS were manufactured by Hamamatsu-Photonics Co.

\section{References}

Anderson, D. E., Jr., Mariner 6, 7, and 9 ultraviolet spectrometer experiment: Analysis of hydrogen Lyman alpha data, J. Geophys. Res., 79, 1513-1518, 1974.

Anderson, D. E., Jr. and C. W. Hord, Mariner 6 and 7 ultraviolet spectrometer experiment: Analysis of hydrogen Lyman-alpha data J. Geophys. Res., 76, 6666-6673, 1971.

Barth, C. A., C. W. Hord, J. B. Pearce, K. K. Kelly, G. P. Anderson, and A. I. Stewart, Mariner 6 and 7 ultraviolet spectrometer experiment: Upper atmosphere data, J. Geophys. Res., 76, 2213-2227, 1971.

Barth, C. A., C. W. Hord, A. I. Stewart, and A. L. Lane, Mariner 9 ultraviolet spectrometer experiment: Initial results, Science, $\mathbf{1 7 5}$ 309-312, 1972

Bougher, S. W., R. G. Roble, E. C. Ridley, and R. E. Dickinson, The Mars thermosphere, 2. General circulation with coupled dynamics and composition, J. Geophys. Res., 95, 14811-14827, 1990.

Carr, M. H., Mars: A water-rich planet?, Icarus, 68, 187-216, 1986.

Dementyeva, N. N., V. G. Kurt, A. S. Smirnov, L. G. Titarchuk, and S. D. Chuvahin, Preliminary results of measurements of UV emissions scattered in the Martian upper atmosphere, Icarus, 17, 475-483, 1972.

Fox, J. L., Airglow and aurora in the atmospheres of Venus and Mars, in Venus and Mars: Atmospheres, Ionospheres, and Solar Wind Interactions, edited by J. G. Luhmann, M. Tatrallyay, and R. O. Pepin, pp. 191-222, Geophysical Monograph 61, AGU, 1992.

Fox, J. L. and A. Dalgarno, Ionization, luminosity and heating of the upper atmosphere of Mars, J. Geophys. Res., 84, 7315-7333, 1979.

Fox, J. L. and A. I. F. Stewart, The Venus ultraviolet aurora: A soft electron source, J. Geophys. Res., 96, 9821-9828, 1991.

Gullikson, E. M., R. Korde, L. R. Canfield, and R. E. Vest, Stable silicon photodiodes for absolute intensity measurements in the VUV and soft X-ray regions, J. Electron Spectrosc. Related Phenomena, 80, 313-316, 1996.

Haider, S. A., J. Kim, A. F. Nagy, C. N. Keller, M. I. Verigin, K. I. Gringauz, N. M. Shutte, K. Szego, and P. Kiraly, Calculated ionization rates, ion densities, and airglow emission rates due to precipitating electrons in the nightside ionosphere of Mars, J. Geophys. Res., 97, 10637-10641, 1992

Ip, W.-H., On a hot oxygen corona of Mars, Icarus, 76, 135-145, 1988 Ip, W.-H., The fast atomic oxygen corona extent of Mars, Geophys. Res. Lett., 17, 2289-2292, 1990.

Kawahara, T. D., S. Okano, T. Abe, H. Fukunishi, and K. Ito, Glass-type hydrogen and deuterium absorption cells developed for $\mathrm{D} / \mathrm{H}$ ratio measurements in the Martian atmosphere, Appl. Opt., 36, 22292237, 1997.

Krasnopolsky, V. A., Atomic carbon in the atmosphere of Mars and
Venus, Cosmic Res., 20, 430-437, 1983.

Krasnopolsky, V. A. and A. A. Krysko, On the night airglow of the Martian atmosphere, Space Res. XVI, 1005-1008, 1976.

Kurt, V. G., A. S. Smirnov, L. G. Titarchuk, and S. D. Chuvahin, Observation of OI $1300 \AA$ radiation in the Martian atmosphere, Icarus, 21, 35-41, 1974.

Levine, J. S., D. S. McDougal, D. E. Anderson, Jr., and E. S. Barker, Atomic hydrogen on Mars: Measurements at solar minimum, Science, 200, 1048-1051, 1978.

McElroy, M. B., Mars: An evolving atmosphere, Science, 175, 443445, 1972.

McElroy, M. B. and J. C. McConnell, Atomic carbon in the atmospheres of Mars and Venus, J. Geophys. Res., 76, 6674-6690, 1971.

McElroy, M. B., T. Y. Kong, and Y. L. Yung, Photochemistry and evolution of Mars' atmosphere: A Viking perspective, J. Geophys. Res., 82, 4379-4388, 1977.

Meier, R. R. and J.-S. Lee, An analysis of the OI 1304 A dayglow using a Monte Carlo resonant scattering model with partial frequency redistribution, Planet. Space Sci., 30, 439-450, 1982.

Mumma, M. J., H. D. Morgan, and J. E. Mentall, Reduced absorption of the nonthermal $\mathrm{CO}\left(\mathrm{A}^{1} \Pi-\mathrm{X}^{1} \Sigma^{+}\right)$fourth-positive group by thermal $\mathrm{CO}$ and implications for the Mars upper atmosphere, J. Geophys. Res., 80, 168-172, 1975.

Nagy, A. F. and T. E. Cravens, Hot oxygen atoms in the upper atmospheres of Venus and Mars, Geophys. Res. Lett., 15, 433-435, 1988.

Nagy, A. F., T. E. Cravens, J.-H. Yee, and A. I. F. Stewart, Hot oxygen atoms in the upper atmosphere of Venus, Geophys. Res. Lett., 8, 629632,1981

Nier, A. O. and M. B. McElroy, Composition and structure of Mars's upper atmosphere: Results from the neutral mass spectrometers on Viking 1 and 2, J. Geophys. Res., 82, 4341-4349, 1977.

Owen, T., J. P. Maillard, C. de Bergh, and B. L. Lutz, Deuterium on Mars: The abundance of HDO and the value of D/H, Science, 240, 1767-1770, 1988.

Paxton, L. J. and D. E. Anderson, Far ultraviolet remote sensing of Venus and Mars, in Venus and Mars: Atmospheres, Ionospheres, and Solar Wind Interactions, edited by J. G. Luhmann, M. Tatrallyay, and R. O. Pepin, pp. 113-189, Geophysical Monograph 61, AGU, 1992.

Paxton, L. J. and R. R. Meier, Reanalysis of Pioneer Venus Orbiter Ultraviolet Spectrometer data: OI 1304 intensities and atomic oxygen densities, Geophys. Res. Lett., 13, 229-232, 1986.

Pearce, J. B., K. A. Gause, E. F. Mackey, K. K. Kelly, W. G. Fastie, and C. A. Barth, Mariner 6 and 7 ultraviolet spectrometers, Appl. Opt., 10, 805-812, 1971 .

Phillips, J. L., A. I. F. Stewart, and J. G. Luhmann, The Venus ultraviolet aurora: Observations at $130.4 \mathrm{~nm}$, Geophys. Res. Lett., 13, 1047-1050, 1986.

Stewart, A. I. F., C. A. Barth, C. W. Hord, and A. L. Lane, Mariner 9 ultraviolet spectrometer experiment: Structure of Mars' upper atmosphere, Icarus, 17, 469-474, 1972.

Stewart, A. I. F., M. J. Alexander, R. R. Meier, L. J. Paxton, S. W. Bougher, and C. G. Fesen, Atomic oxygen in the Martian thermosphere, J. Geophys. Res., 97, 91-102, 1992.

Strickland, D. J., A. I. Stewart, C. A. Barth, C. W. Hord, and A. L. Lane, Mariner 9 ultraviolet spectrometer experiment: Mars atomic oxygen 1304-Å emission, J. Geophys. Res., 78, 4547-4559, 1973.

Taguchi, M., T. D. Kawahara, Y. Ito, and K. Ito, Evaluation of new hydrogen and deuterium absorption cells for PLANET-B/UVS, PF Activity Rep., 14, 280, 1997.

Thomas, G. E., Neutral composition of the upper atmosphere of Mars as determined from the Mariner UV spectrometer experiments, $J$. Atmos. Sci., 28, 859-868, 1971.

Yamamoto, T. and K. Tsuruda, The PLANET-B mission, Earth Planets Space, 50, 175-181, 1998.

M. Taguchi (e-mail: taguchi@nipr.ac.jp), H. Fukunishi, S. Watanabe, S. Okano, Y. Takahashi, and T. D. Kawahara 